\title{
Narrativas de crianças sobre as escolas da infância: cenários e desafios da pesquisa (auto)biográfica
}

Children stories about primary schools: sceneries and (auto)biographic research challenges

Maria da Conceição Passeggi*

Universidade Federal do Rio Grande do Norte

Ecleide Cunico Furlanetto**

Universidade Cidade de São Paulo

Luciane De Conti***

Universidade Federal de Pernambuco

Iduina Edite Mont'Alverne Braun

Chaves****

Universidade Federal Fluminense

\author{
Marineide de Oliveira Gomes***** \\ Universidade Federal de São Paulo \\ Gilvete Lima Gabriel****** \\ Universidade Federal de Roraima \\ Simone Maria da Rocha******* \\ Universidade Federal do Rio Grande do Norte
}

Resumo Este trabalho focaliza narrativas de crianças de 04 a 10 anos de idade, e investiga como elas dão sentido às experiências vividas na escola. A reflexão resulta de um projeto de pesquisa interinstitucional, realizado em escolas de Natal, São Paulo, Recife, Niterói e Boa Vista. Para a recolha das fontes, optou-se por rodas de conversas com grupos de cinco crianças que dialogavam com um pequeno alienígena, em cujo planeta não tinha escolas. Das análises, emergem consensos e tensões entre modos de ser criança e modos de ser aluno, que afetam suas relações com o brincar e o aprender; o fazer ou não fazer amigos; ser ou não ser criança. Ao narrar, elas ressignificam suas experiências e contribuem para a compreensão das escolas da infância como lugar no qual a criança se constitui (ou não) como sujeito de direito.

PALAVRAS-CHAVE: Narrativas infantis, Escolas de Infância, Pesquisa (auto) biográfica.

Abstract This study deals with 4-10 year-old children stories and analyses how they portrait their experiences at school. It is the outcome of an inter-institutional research project performed at schools in Natal, São Paulo, Recife, Niterói and Boa Vista. To collect data, we opted for conversations of children in groups of five, who would share a conversation with a little alien whose planet lacked schools. The analyses revealed consensus and tensions between scholar culture and childhood cultures, which affect the way children play and learn, make friends or not, remain children or not. When narrating, the child redefines his/her experience and contributes to seize the primary school as a place where he/she becomes (or not) a citizen.

KEYWORDS: Children stories, Primary schools, (Auto)biographicresearch. 


\section{Em guisa de introdução}

Ainda são recentes, entre nós, estudos e pesquisas que garantam a centralidade da criança como sujeito de direito e que busquem compreendê-la na sua inteireza de pensamento, movimento, ação, emoção e, especialmente, que reconheçam suas formas de ver e representar o mundo da vida como modos legítimos de ser e de viver em sociedade. A partir dos anos 1990, multiplicaram-se os trabalhos empreendidos no âmbito da Sociologia da Infância em defesa de uma (r)evolução, que vem permitindo operar a passagem da representação da criança como um "vir-a-ser-humano", que a tornava «invisível», para aquela de sujeito de direito. Uma extensa e rica bibliografia publicada nessa direção dá conta dos avanços científicos e o interesse crescente por essa área de investigação, na qual se incluem os trabalhos de Sarmento (1997, 2005); Sarmento e Vasconcelos (2007); Sarmento e Pinto (1997); Gouvêa (2008); Corsaro (2009); Delalande, J. et al (2006); Cruz, (2008); Müller (2010); Müller e Carvalho, (2009); Prout (2010), Lee (2010) entre tantos outros.

A "promessa de 'um lugar global' para as crianças", como lembra Lee (2010, p. 49), foi instituída desde 1989, pelo Art. 12 da Convenção das Nações Unidas sobre os Direitos da Criança (Assembleia Geral das Nações Unidas, 1989), que lhe assegura o direito de inserir "sua voz", sua palavra "nos processos de tomada de decisão do Estado". No entanto, para Lee (op. cit), o artigo gerou ambiguidades sobre a condição de vida das crianças: "Se elas não são claramente um "vir-a-ser", então não podem ser protegidas; se não são claramente "ser", então não podem ser respeitadas". Ambiguidades que permeiam as ações nos campos jurídico e educacional e que exigem de pesquisas e posicionamentos políticos suscetíveis de contribuírem para que se efetive na prática, a percepção da criança como sujeito de direito, para além de qualquer ambiguidade.

O presente trabalho se insere nesse debate com base em reflexões conduzidas pelas autoras no projeto de pesquisa: "Narrativas infantis. O que contam as crianças sobre as escolas da infância?”, financiado pelo CNPq e CAPES'1. O grupo de pesquisadoras têm vínculos tecidos há mais de dez anos, em torno da pesquisa com narrativas autobiográficas, entendidas como método e prática de formação, e vêm buscando conjugar as áreas de Educação e de Psicologia em perspectivas complementares.No projeto, partimos da seguinte provocação como questão norteadora da pesquisa: $O$ que diz a criança sobre as escolas da infância é digno de interesse para a pesquisa educacional sobre crianças? A formação de professores? As Politicas Públicas em Educação para a infância?

A proposta visa a olhar a infância de modo a levar em conta a alteridade da criança, legitimando-a como ser capaz de refletir ao narrar suas vivências e, por essa via, trazer informações importantes sobre as escolas da infância e sobre a criança-sujeito. Nesse sentido, a reflexividade na infância, sobre a qual se baseia o projeto, permeia as nossas reflexões e vai ao encontro das investigações realizadas nos últimos anos por pesquisadores preocupados em conferir à criança o estatuto de sujeito de direito, conforme atestam as publicações mais recentes nessa área.

Sabemos, no entanto, que realizar o que hoje compreendemos por "pesquisa com crianças" implica novas questões epistemológicas, éticas e de métodos, desde a concepção do projeto até a publicação de seus achados. O nosso propósito aqui é 
partilhar modos de abordagem e de interpretação, ancorados em princípios e métodos da pesquisa (auto)biográfica em Educação com entradas em correntes da Psicologia,que trabalham com narrativas. Ambicionamos contribuir, por um lado, para ampliar o repertório de práticas de investigação e de análise da "voz da criança"e, por outro lado, para o debate conduzido nas pesquisas com crianças acerca da práxis pedagógica com vista à formação de professores da infância e à construção e legitimação de políticas públicas para instituições de acolhimento da criança, de modo que assegurem o seu direito na definição de tais políticas e decisões para o seu acolhimento nas instituições a ela destinadas.

Organizamos este texto em duas partes. Na primeira, definiremos o quadro teórico e metodológico da pesquisa, na segunda, buscamos tematizar, com as crianças, e a partir do que elas nos contaram, a travessia que realizam da Educação Infantil para o Ensino Fundamental. O interesse é interpretar, com elas, a forma como vão tecendo suas experiências ao percorrer as diferentes etapas desse percurso, e como vão negociando seus pertencimentos à escola, que lhes impõe seus tempos e rituais próprios.

Nosso intuito é compreender, numa perspectiva dialógica, a socialização e a subjetivação, como duas faces indissociáveis no processo de inserção da criança no mundo da escola. Para examinar eventuais conflitos, suscetíveis de afetar a criança, quanto ao seu pertencimento ou, ao contrário, quanto a dissidências a curto e longo prazo, adotamos a noção de enculturação, utilizada por Bruner (1997) e definida por Rivière,(1999, p. 183, tradução nossa), como "ao mesmo tempo, a transmissão da cultura de uma geração a outra e a maneira como a identidade pessoal se constrói, assumindo, em grande parte, os traços específicos da sociedade a qual se pertence". Correia (2003, p. 508), lembra que para Bruner a Psicologia Cultural, eminentemente interpretativa, está "interessada nas formas através das quais os seres humanos produzem significados nos contextos culturais onde estão inseridos. As pessoas são resultado deste processo de produção de significados, no qual a educação está intimamente relacionada como contexto cultural situado".

\section{Quadro teórico e metodológico da pesquisa}

\section{Narrativa e reflexividade autobiográfica na infância}

Quanto mais formos capazes de nos dar conta e de dar conta aos outros da experiência vivida, mais ela será vivida conscientemente (experimentada, fixada na palavra etc.). (VYGOTSKI, 2003, p. 78, tradução nossa).

Por que privilegiar as narrativas de crianças sobre a escola como instrumento de pesquisa e objeto de estudo? Em primeiro lugar, porque levamos a sério o esforço que elas fazem para compreender e explicar o que sentem, desejam ou não desejam... Em seguida, porque concordamos com Larrosa (2010, p. 184), que a infância desestabiliza "a segurança de nossos saberes, questiona o poder de nossas práticas e abre um vazio em que se abisma o edifício bem construído de nossas instituições de acolhimento". Finalmente, porque ao considerar as narrativas de crianças como objeto de estudo, retomamos uma tradição de pesquisa iniciada por Bruner, no âmbito da Psicologia Cultural, que nos revela as potencialidades heurísticas da reflexão das próprias crianças sobre elas mesmas, o que faz dessas narrativas o material mais adequado para compreender a infância. 
É ao que nos convidam Bruner e Weisser (1997, p. 149 sg.) ao analisarem as narrativas de uma criança entre dois e três anos de idade. Todas as noites, antes de dormir, Emmy contava histórias para seus bichinhos de pelúcia e narrava o que the acontecia. Por exemplo, como tinha sido "despejada" do seu quarto depois do nascimento do irmão e como vivia sua entrada na pré-escola, que começara a frequentar logo após a chegada dele. A tarefa de Emmy, como a de toda criança, era se localizar na corrente desses acontecimentos. Para os autores, essa era "uma tremenda tarefa interpretativa" que Emmy buscava dominar mediante uma narrativa, não escrita, espontânea e interpretativa a respeito de si, ou seja, ela ensaiava seus primeiros esboços de uma "autobiografia" não intencional.

Ao narrar, Emmy reelabora temas “complexos e dramáticos" da experiência vivida, não necessariamente, para resolver seus dramas, mas para conferir aos acontecimentos um sentido. É essa disposição do humano para a reflexão sobre si mesmo que chamaremos de reflexividade autobiográfica. As palavras de Vygotski, citadas na epígrafe, nos falam dessa função psíquica, propiciada pelo ato de narrar, permitindonos vivenciar, mais conscientemente, a nossa própria experiência no esforço de explicitá-la para nós mesmos ou para o outro. E, nesse trabalho, as palavras vão fixando as experiências vividas mediante a tarefa de interpretação, em que entram em jogo a memória e a constituição da identidade do narrador que se examina como personagem de sua narrativa. Esse esforço humano de reflexividade autobiográfica torna as narrativas produzidas pela criança, acerca de suas experiências, um objeto de estudo precioso para o acesso às construções que elas fazem a respeito do que vivem na escola.

Do ponto de vista textual, a narrativa é concebida como uma sequência singular de eventos, estados mentais, ocorrências, envolvendo seres humanos como personagens da ação. Cada elemento constitutivo da narrativa adquire sentido a partir do lugar que os personagens ocupam no enredo e essa sucessão depende da intencionalidade do narrador em suas relações com quem o escuta ou o lê. De modo que a sucessão dos fatos em uma narrativa é 'imposta', segundo Ricoeur (1994), pela própria tessitura da intriga e responde a uma necessidade lógica, que vai se constituindo no próprio ato de narrar, e não por uma exigência externa, cronológica, linear.

É importante salientar que as formas narrativas existentes em nossa cultura são transmitidas de uma geração para outra. Na concepção de Dunn (1988), isso se realiza nas primeiras interações entre a criança e o adulto responsável por ela. Para a autora, o entendimento social começa como práxis em contextos particulares, nos quais a criança é protagonista, agente, vítima ou cúmplice. Ela aprende a desempenhar um papel no "drama" cotidiano familiar, antes que se exija dela qualquer narração, justificativa ou desculpa. É desse modo, que a criança entra no campo da interpretação da cultura. A narrativa torna-se um instrumento nos conflitos familiares, tanto para contar o que aconteceu, quanto para oferecer uma justificativa para a ação relatada. Nessa direção, Smith, Bordini e Sperb (2009) asseveram que podemos considerar a narrativa como um aspecto prioritário do desenvolvimento a ser oportunizado e promovido na escola infantil, coerente com o caráter amplo, lúdico e das transições nesse contexto. As autoras salientam, ainda, a necessidade de investigar as oportunidades e a qualidade da interlocução que valorizem as narrativas de crianças no cotidiano das escolas brasileiras. A utilização de histórias orais é uma prática comum em todas as épocas e lugares. De forma ritualizada e cotidiana, a narrativa atende a múltiplas funções essenciais à vida numa cultura: a comunicação, a explicação de motivações 
para comportamentos e causas, a persuasão, a criação de versões para acontecimentos, o entretenimento, a construção de mundos e situações possíveis, conforme lembram Smith e Sperb (2007).

Finalmente, admitimos que, pela reflexividade autobiográfica, a criança dota-se da possibilidade de se desdobrar como espectador e como personagem do espetáculo narrado; como pensador e como objeto pensado; enfim, como objeto de reflexão e como ser reflexivo. Essa relação dialógica entre o ser e a representação de si que se realiza pela reflexividade autobiográfica confere à criança, ao jovem, ao adulto um modo próprio de existência, pela probabilidade de voltar-se sobre si mesmo para explicitar o que sente, ou até mesmo perceber que fracassa nessa difícil tarefa de (re) elaborar a experiência vivida, com a ajuda da linguagem em suas mais diversas formas.

Concordamos com Ferreira (2008, p. 153) ao insistir, por sua vez, sobre a noção de reflexividade para focalizar também o ponto de vista do pesquisador, questionar suas "práticas de investigação e os processos de produção de conhecimento". Nessa dupla perspectiva, organizamos nosso pensamento, entendendo que essa disposição (e não competência ou capacidade) à reflexividade, que emerge na infância e se prolonga ao longo da vida, é uma "marca do humano", como diria Pino (2005). Daí o interesse de problematizar na pesquisa educacional, a sua importância para a produção de conhecimentos, com as crianças, sobre elas, e as instituições que as acolhem na infância.

\section{A pesquisa com narrativas em Educação e em Psicologia}

No campo da pesquisa educacional com crianças, situamo-nos na perspectiva da pesquisa (auto)biográfica em Educação e de correntes da Psicologia, que tomam as narrativas em uma perspectiva narrativista (Moutinho e De Conti, 2010). Conforme afirma Passeggi (2011, p.13), as histórias de vida e o biográfico (escrita da vida) retornam como objeto de pesquisa nas Ciência Humanas e Sociais, nos anos 1980, momento que se caracteriza pela instabilidade epistemológica decorrente do declínio dos grandes paradigmas.A pesquisa (auto)biográfica se inscreve nos desdobramentos desse movimento científico e cultural e tomará as narrativas de si "enquanto fontes de investigação privilegiadas, suscetíveis de revelar os modos como se tecem os vínculos entre o sujeito e o mundo nas esferas sociais onde ele vive e interage". Christine Delory-Momberger (2012, p. 524-525, grifos da autora), assim define essa jovem ciência:

Alimentada por uma ampla tradição hermenêutica (Dilthey, Gadamer, Ricœur) e fenomenológica (Berger, Luckmann, Schapo, Schütz), a pesquisa biográfica estabelece uma reflexão sobre o agir e o pensar humanos,mediante figuras orientadas e articuladas no tempo que organizam e constroem a experiência segundo a lógica de uma razão narrativa.

Nessa direção, a atividade de biografização ocupa um lugar central do ponto de vista teórico e epistemológico, pois se admite como princípio que o "humano apreende e vive cada instante de sua vida como o momento de uma história: história de um instante, história de uma hora, de um dia, de uma vida" (ib. p. 525). Para DeloryMomberger (ib. p. 525), a atividade de biografização não se restringe, portanto, a um ato discursivo, mas se caracteriza como 
Maria da Conceição Passeggi - Ecleide Cunico Furlanetto - Luciane De Conti

Iduina Edite Mont'Alverne Braun Chaves - Marineide de Oliveira Gomes

Gilvete Lima Gabriel - Simone Maria da Roch

uma atividade mental e comportamental, uma forma de compreensão e de estruturação da experiência e da ação, exercendo-se de forma constante na relação do homem com a sua vivência e com o mundo que o rodeia. [E compreende] todas as operações mentais, comportamentais e verbais pelas quais o indivíduo não cessa de inscrever sua experiência e sua ação em esquemas temporais orientados e finalizados.

Em Psicologia, os trabalhos inaugurais de Jerome Bruner, no âmbito da Psicologia Cultural, inspirada na perspectiva vygotskiana e de seus seguidores, constituem as referências fundantes para o desenvolvimento, a partir dos anos 1980, do que Brockmeier e Harré (2003, p. 525) consideram a "virada discursiva e narrativa, na Psicologia e nas outras ciências humanas". Macedo (2006, p. 512) lembra que "Bruner sugere uma Psicologia interpretativa, que busque "as regras que os seres humanos aplicam para a produção de significado em contextos culturais (Bruner, 1997, p. 102)”.

A pesquisa (auto)biográfica e a Psicologia narrativa, ou interpretativa, partilham um pressuposto comum:

[As] narrativas são formas inerentes em nosso modo de alcançar conhecimentos que estruturam a experiência do mundo e de nós mesmos. Em outras palavras, a ordem discursiva através da qual nós tecemos nosso universo de experiências emerge apenas como um modus operandi do próprio processo narrativo. Ou seja, estamos lidando primariamente não com um modo de representação, mas com um modo específico de construção e constituição da realidade, como Bruner (1991) apontou. (BROCKMEIER; HARRÉ, 2003, p. 531)

Por partilharem referências teóricas, princípios e modos de abordagem comuns, buscamos aprofundar a interação entre esses dois campos, assumindo-os como complementares, em nossos grupos de pesquisa.Com base nessas perspectivas, admitimos como hipótese que a consciência de si emerge na atividade de biografização, no momento mesmo em que a criança conta o que lhe acontece. Esse processo de conhecimento de si, mediante o ato de narrar, foi um dos argumentos utilizado para formular riscos e benefícios da pesquisa para as crianças que participaram do projeto, como parte de nossa preocupação com a ética na pesquisa.

\section{Cenários da pesquisa}

A recolha dos dados da pesquisa foi realizada pelas próprias pesquisadoras, em 2012-2013, em três regiões brasileiras - Norte, Nordeste e Sudeste - nos municípios de Natal (RN), São Paulo (SP), Niterói (RJ), Recife (PE) e Boa Vista (RR). Foram escolhidas escolas vinculadas às universidades federais, implicadas na pesquisa (UFRN, Unifesp, UFF), uma escola da rede municipal, em Recife, e a escola de uma comunidade indígena, que reúne crianças de três etnias: Macuxi, Taurepang e Wapixana. Como critérios de escolha, decidimos por aquelas que acolhem crianças de diferentes origens sociais com o propósito de cruzar informações que possam dar início a um primeiro mapeamento de escolas da infância a partir da visão de mundo de crianças representativas de parte da diversidade cultural país. As escolas da infância serão aqui entendidas como lugar de continuidade e não fragmentação, nem hierarquização entre as etapas da educação infantil e dos anos iniciais do ensino fundamental, que atendem crianças de zero a dez anos de idade. 
A escolha da faixa etária -de 04 a 10 anos de idade - situa a proposta numa perspectiva transversal, pois visa a observar como evoluem, ou não, em suas narrativas, os modos de significar a travessia da educação infantil para o ensino fundamental. Nesse sentido, buscamos compreender a criança em seu duplo estatuto: o estatuto de criança pequena que ingressa no mundo escolar bem mais diversificado do que o universo familiar, e o estatuto de aluno(a)s na interação com esse universo escolar, considerando-os como sujeitos de direito e de sua formação intelectual e pessoal (SACRISTÁN, 1999).

\section{Recolha das fontes}

O método de recolha das fontes foi o mesmo para as cinco equipes. Optamos por rodas de conversa, com no máximo 05 crianças, e no mínimo 03, assim distribuídas: Grupo 1: crianças de quatro a cinco anos; Grupo 2: crianças de cinco a seis; Grupo 3: crianças sete aoito; Grupo 4: crianças de nove a dez anos. Participaram da pesquisa o total de 75 (setenta e cinco) crianças. As rodas de conversa foram gravadas em áudio e em vídeo e, posteriormente, transcritas. Colocamos a disposição das crianças pequenas câmeras para que elas manuseassem e assim gravessem as entrevistas dos colegas, além de outros recursos de registro como papel e lápis.

Quanto à forma de desencadear a conversa, partilhamos também um protocolo comum, inspirado no protocolo do projeto "Raconterl'écoleencours de scolarisation" [Falar sobre a escola durante a escolarização], coordenado por Martine Lani-Bayle, pesquisadora da Université de Nantes, do qual participam colegas de mais quatro países e ao qual o nosso projeto se vincula.

A roda de conversa se organiza em função da presença de um pequeno alienígena que vem visitar a escola. Tínhamos como opção dois brinquedos: o Alien, personagem do alienígena no filme Toy Story (Pixar, 1995) e um sapinho com asas, feito de tecido. A ideia do alienígena é a de provocar o distanciamento necessário a imaginação e a reflexão crítica, consideradas necessárias a um movimento de negociação cultural, de modo a dar possibilidades da criança com eventuais conflitos e desenvolver meios de sedução e de persuasão, ao se situar diante do alienígena, para envolvê-lo naquilo que diziam. $\mathrm{O}$ alienígena desempenhava, assim, a função de mediador da construção narrativa, permitindo maior familiarização da criança com o pesquisador, que tenta se aproximar do universo infantil e das crianças respeitando as diferenças entre eles.

As rodas foram estruturadas em torno de três momentos: abertura, desenvolvimento e fechamento. $\mathrm{Na}$ abertura, nos dirigimos às crianças a partir do pequeno texto, que reproduzimos abaixo, com um único comando: adaptá-lo à idade e às reações da criança, de modo a favorecer um momento de ludicidade e de distanciamento.

Este é um pequeno alienígena (ou Este é o Alien) que mora num planeta onde não tem escolas. Ele veio aqui porque queria que vocês contassem para ele tudo o que vocês sabem sobre a escola. Quem gostaria de explicar para o pequeno extraterrestre como é a escola, para que serve a escola, o que a gente faz aqui...

Para a fase de desenvolvimento, previmos algumas perguntas para explorar a percepção da criança: Como você ajudaria ao Alien a fazer amigos na escola? Ele 
Maria da Conceição Passeggi - Ecleide Cunico Furlanetto - Luciane De Conti

Iduina Edite Mont'Alverne Braun Chaves - Marineide de Oliveira Gomes

Gilvete Lima Gabriel - Simone Maria da Roch

quer saber do que é que mais gosta na escola? Quer dizer para ele? Se você pudesse mudar alguma coisa, você mudaria o quê? $\mathrm{O}$ que não poderia faltar na escola?... O fechamento se dava em função do retorno do pequeno alienígena ao seu planeta. Ao perguntar se queriam enviar uma mensagem para seus amigos, todos desenharam e escreveram para eles.

\section{Procedimentos de análise e publicação}

Transmitir ao leitor os meios para lançar sobre as declarações que vai ler esse olhar que dá razão, que restitui ao pesquisado sua razão de ser e sua necessidade (Pierre Bourdieu, 2003, p. 712).

Nesse exato momento em que escrevemos para publicar o que aprendemos com as histórias que nos foram contadas, desejamos, como sugere Bourdieu, na epígrafe, que o leitor possa lançar, sobre as narrativas das crianças, esse olhar que restitui a elas sua razão de ser e sua necessidade.

O desafio de interpretar a interpretação da criança, em suas pequenas narrativas, tem exigido ainda mais cuidado, ainda mais rigor, para nos aproximarmos de sua visão de mundo, sem nos deixar envolver pelo óbvio ou pelo espírito de análise e preocupações teóricas que venham a por em risco o modo de pensar da criança. Duas soluções eram possíveis, ambas difíceis: substituir as complexas análises pelas palavras das próprias crianças, como fez com maestria Pierre Bourdieu (2003), com as histórias de seus entrevistados em $A$ Miséria do Mundo, ou então, proceder a um processo interpretativo que permitisse reconstruir, pelo menos em parte, do que sugere Bruner (1998, p.15): dois "panoramas simultaneamente", um "panorama da ação"e um "panorama da consciência". Optamos pelo segundo com todos os seus riscos e desafios.

Começamos por adotar, com Bertaux (2010, p. 18, grifos do autor), uma concepção minimalista de narrativa: "existe narrativa de vida desde que haja descrição sob forma narrativa de um fragmento da experiência vivida". E uma concepção minimalista de biografização, sugerida por Delory-Momberger (2012), ao se referir à "história de um instante, história de uma hora, de um dia"..., pois a criança biografa nas rodas de conversa, com frases curtas e breves, suas experiências. Assim, para as análises, consideramos excertos como este de Guy (5 anos), que biografa um fragmento da experiência vivida, para dar conta de como e do quanto ele cresceu: "Um dia, eu cresci, aí... eu cresci desse tamanho (abrindo bem os braços). "Consideramos ainda, as narrativas elaboradas coletivamente: Lia, Natália e Tobias constroem juntos esta narrativa: "Eu acho que já vi esse filme"; "É um desenho animado"; "E tem um colega de quarto" (referiam-se ao filme "Família do futuro").

Retomamos, nos procedimentos da pesquisa, o que aconselha Bourdieu (2003) sobre os riscos de violência simbólica em três etapas cruciais do arco da produção do conhecimento com narrativas autobiográficas orais: recolha das narrativas, textualização - análise; publicação.

Na recolha dos dados, a entrevista é considerada pelo autor (ib. 704) como um "exercício espiritual visando a obter pelo esquecimento de si uma verdadeira conversão do olhar que lançamos sobre os outros nas circunstâncias comuns da vida". Quanto ao trabalho de transcrição, textualização e análises, recomenda que, por res- 
peito ao narrador, a transposição para a escrita deve ser capaz de "tocar e de comover, de falar à sensibilidade, sem sacrificar ao gosto do sensacional” (ib., p. 711). As operações envolvidas, nessa transposição, fazem do pesquisador um mediador entre o narrador e o leitor. Daí a responsabilidade do pesquisador para criar as condições necessárias à compreensão e à interpretação do que ele percebeu na voz, no olhar, nos movimentos das crianças e nas histórias narradas.

Essa foi uma das razões que nos levou a conduzir, pessoalmente, todas as rodas de conversa com as crianças. Queríamos poder recompor a paisagem externa para tentar descortinar a paisagem interna das emoções, as delas e as nossas, e reflexões no momento da interação. Como lembra Ferrarotti (2010), a entrevista é antes de tudo uma interação social. No que concerne à publicação, Bourdieu (ib.) sugere que o pesquisador vise à democratização da postura hermenêutica, de modo que o leitor conceda às narrativas ordinárias "o acolhimento fervoroso que certa tradição de leitura reserva às formas mais altas da poesia ou da filosofia" (ibidem., p. 712). Essa recomendação é de fato um desafio estimulante para a pesquisa (auto)biográfica com crianças: Como fazer para que o leitor conceda à palavra da criança o mesmo acolbimento fervoroso que ele reserva à palavra do cientista?

Nesse primeiro momento, buscamos mapear os temas que identificamos nas leituras das rodas de conversas e examinar como eles evoluem nos quatro grupos. Adotamos como único critério a variável idade para analisar, numa perspectiva transversal, as mudanças na visão de mundo das crianças. Para encontrar os temas, recopiamos as transcrições na íntegra em páginas com duas colunas. Na coluna à direita, inserimos a transcrição e na coluna à esquerda fomos escrevendo nossos comentários sobre o que nos chamava a atenção. Nessa leitura, íamos colorindo os temas identificados com cores diferentes para facilitar, depois, a sua organização em núcleos de sentido, com seus tópicos específicos. Nos inspiramos para isso no que nos ensina Mills (1982, p. 228-243) sobre "o artesanato intelectual" e as formas de estimular a imaginação sociológica. Não sem dificuldades, fomos organizando, passo a passo, as ideias que iam surgindo e fomos estabelecendo comparações entre as rodas de conversa. Mas, é na escrita das diferentes versões do texto com vista à sua publicação, que o enredo de uma outra narrativa se impõe. E nesse esforço, extremamente heurístico, surgiram os achados que escolhemos partilhar aqui.

O que trazemos são, portanto, as grandes linhas pontuadas pelas crianças em apenas duas das escolas pesquisadas. Nessas primeiras análises, procuramos evidenciar consensos e tensões entre o brincar e o aprender que permeiam as visões das crianças como marco de seu ingresso no universo escolar. Tematizaremos com elas como tentam dar sentido as suas relações com o brincar e o aprender e como vivenciam seus modos de ser criança nas escolas que as acolhem na infância.

\section{O ingresso no mundo da escola: trajetória de um apagamento}

Tem-se então um traço no lugar dos atos, uma relíquia no lugar das performances: esta é apenas o seu resto, o sinal do seu apagamento.

(Michel de Certeau, 2001, p. 99) 
Maria da Conceição Passeggi - Ecleide Cunico Furlanetto - Luciane De Conti

Iduina Edite Mont'Alverne Braun Chaves - Marineide de Oliveira Gomes

Gilvete Lima Gabriel - Simone Maria da Roch

A ampliação da educação básica para nove anos, a obrigatoriedade do ingresso na escola desde os quatro anos de idade, a determinação de uma carga horária, na educação infantil, de no mínimo 800 horas distribuídas em, no mínimo, 200 dias letivos ${ }^{2}$ são medidas que ainda estão longe de ser avaliadas em suas reais repercussões sobre a educação infantil. O que essas alterações na atual Lei de Diretrizes e Base da Educação Nacional (Lei Federal n. 9.394/96), indica é a permanência cada vez mais prolongada da criança na escola. Se, por um lado, trata-se para alguns de uma importante conquista pela ampliação das oportunidades educacionais, por outro lado, colocam a mostra os desafios enfrentados pelas escolas para concretizar o direito de todos à Educação.

Numa das escolas pesquisadas, as crianças ingressam aos 02 anos de idade e nela permanecem em média por sete anos. A cena que analisamos a seguir revela como as que se encontram no final do percurso interpretam o valor dessa experiência. Para responder a curiosidade dessas crianças, a pesquisadora cita os nomes de professoras que foram suas alunas e acrescenta que: para ela "é muita responsabilidade" formar professoras que trabalham com crianças. Prontamente, Lia e Tobias ${ }^{3}$ (09 anos) fazem os seguintes comentários: " $\mathrm{E}$ olha que essas professoras ensinam a gente desde os dois anos!"; "É como se você ensinasse a gente". A interpretação de suas falas como produto cultural revela que as crianças lançam um olhar sobre dois aspectos importantes da experiência vivida na escola: o primeiro concerne a totalidade de sua formação nos sete anos de vivência na escola, enfatizado na expressão: "E olha que..."; o segundo está relacionado à transmissão intergeracional de conhecimentos, e também de modos de ser, próprios da escola: "É como se você [também fosse responsável por nossa formação]". Essa lucidez da criança ao dar sentido às suas relações com a escola nos deixa à vontade para assumir, em nossos comentários, a responsabilidade dos erros e acertos dessa transmissão intergeracional.

As palavras de Michel de Certeau, na epígrafe, nos ajudam a sintetizar o que emana das rodas de conversa nas escolas pesquisadas até o momento. É possível perceber que o ambiente educacional, nessas escolas de educação infantil (pré-escola e anos iniciais do ensino fundamental), nas quais observamos o cuidado em garantir às crianças espaços de brincadeiras e de aprendizagens, o processo de enculturação no universo escolar está marcado, para elas, por um duplo deslocamento, que implica uma série de acontecimentos, dentro dos quais precisam aprender a se situar: o primeiro é deslocamento da necessidade de brincar para a necessidade de estudar. $\mathrm{O}$ segundo decorre do primeiro: a sobreposição do estatuto de aluno (a), ao de criança. O que faz dessa trajetória um processo gradual de apagamento progressivo da brincadeira na escola e em seguida em suas vidas.

Certamente, cada adulto escolarizado, pode perceber, ao contar suas memórias da infância, como foram se transformando em relíquias as recordações singulares de sua trajetória na escola. As pesquisas realizadas na França, com pessoas entre 40 e 80 anos de idade, sinalizam o quanto a escolaridade - com seus aspectos agradáveis e traumatizantes - está prestes a ressurgir a qualquer idade. Para Lani-Bayle (2000), o lado afetivo do humano, junto com todos os transtornos que podem acompanhá-lo, é primordial e dominante em todo processo de escolarização e em toda sua extensão.

O que é paradoxal, no entanto, é que apesar de estudos e pesquisas confirmarem a importância do brincar para a criança, assunto sobre o qual se debruçaram 
os mais eminentes psicólogos da infância no decorrer do século XX, entre os quais Vygotski (1989) e Bruner (1997), para citar apenas os que nos inspiram aqui, sabemos o quanto vão se tornando cada vez mais raros momentos de ludicidade na escola.

Como insiste Fortuna (2013),muitos educadores constroem sua identidade profissional em função da oposição entre o brincar e o estudar, de modo que a escola vai minando esses espaços de imaginação criativa por não compreender, comVygotsky (1989, p. 105), que "o brinquedo preenche as necessidades da criança" e as teorias e práticas que ignoram esse fato "nada mais são do que uma intelectualização pedante da atividade de brincar". Não é sem razão, que a utilização de escritas em si como dispositivos de formação docente, tais como memoriais, ensaios autobiográficos, narrativas de formação ${ }^{4}$, permita aos professores-narradores, no exercício de reflexão sobre seu percurso escolar, se apropriarem de conhecimentos tácitos sobre a infância e por esse viés se tornarem mais sensíveis aos modos de ser criança.

Como já anunciamos, não se trata, aqui, de analisar o que as crianças vivenciam na escola, em termos de estudar, brincar, aprender, mas de focalizar como dizem que experienciam essas atividades na escola, como dão sentido a elas, como insinuam ou silenciam o que as afeta ao longo desses primeiros anos na escola.

\section{O ingresso na escola. Grupo 1: a escola é lugar de brincar}

Nas narrativas de crianças entre quatro e cinco anos, a experiência escolar aparece entrelaçada aos seus desejos de brincar. Mateus diz para o pequeno alienígena que "na escola tem roda, na escola tem roda final, tem parque, tem brinquedoteca, biblioteca". Para Samara e Natacha, na escola "tem livro para ler", "livro para ver" e "Ele (o ET) está feliz porque ele tá na escola". Durante toda a conversa, não mencionam a palavra estudar ou aprender. A escola é lugar de brincar, em que os livros e os brinquedos se misturam e se alternam na biblioteca, na brinquedoteca e também no parque. Chamou nossa atenção o fato de não mencionarem a sala de aula. O que nos revela esse silêncio?

\section{Início da transição. Grupo 2 - a escola é "pra tudo"}

A transição para uma outra percepção da escola começa a se fazer sentir nas rodas de conversa de crianças com 05 e 06 anos. Em suas narrativas, emerge, pela primeira vez, o "estudar". Para Guy, Zaza e Guto, a escola "é pra tudo", "Pra estudar e fazer... ler...ler... ler... essas coisas"; "Fazer atividade", "Pra estudar e ler livro","E também pra... pra saber tudo". Todos se biografam coletivamente dizendo que gostam da escola: "Eu gosto mais [daqui]"; "Porque [aqui] é legal"; "É legal e bom... tem... tem livros...tem lápis"; "Tem parque”. A escola aparece em suas pequenas narrativas como um espaço que reúne o brincar e o estudar. O estudar, por sua vez, está associado a ler...ler... e a fazer atividades, aos livros e aos lápis. É fácil perceber que aos seis anos descortina-se para elas o mundo da leitura e da escrita de tal forma relacionados ao brincar que as crianças desse grupo biografam a escola como um espaço de "totalidade": A escola "é pra tudo", "pra saber tudo", "ler...ler... ler...essas coisas". Aprender a ler faz parte do processo iniciático de escolarização. Os ritos de consagração e de exclusão, na escola, passam para elas por essa travessia da oralidade à escrita. $\mathrm{O}$ ethos de leitor, bom leitor, mau leitor começa a se delinear, para cada um, como possibilidades de ser aluno, o que se consolida na roda de conversa do grupo 3, com crianças de 06 a 08 anos. 
Maria da Conceição Passeggi - Ecleide Cunico Furlanetto - Luciane De Conti

Iduina Edite Mont'Alverne Braun Chaves - Marineide de Oliveira Gomes

Gilvete Lima Gabriel - Simone Maria da Roch

\section{A transição. Grupo 3: a escola é para estudar e "brincar um pouco"}

A separação entre o brincar e o estudar se configura com mais clareza nas rodas de conversa com crianças entre 06 e 08 anos de idade. Elas vão explicando para o pequeno ET o sentido que dão a escola: "Nós estudamos, fazemos lição e prova"; "A gente brinca, faz recreação"; "A gente brinca um pouco, depois a gente estuda". Nas duas escolas, elas confirmam essa divisão do tempo e dos modos como se sucedem o brincar e o aprender. A escola serve para "estudar"; "E também pra aprender"; "Brincar"; "Conseguir ler"; "Ajudar as crianças a escrever"; "Serve pra muitas coisas". Palavras como "lição", "prova", "recreação" sinalizam a incorporação de valores e crenças que justificam os ritmos dos tempos do brincar e do aprender, por vezes, distantes dos ritmos da vida fora da escola.

Em seus modos de narrar, elas se biografam segundo os critérios transmitidos pela escola como crianças leitoras ou ainda não leitoras. Liliana (06 anos) coloca em cena os colegas Lana e Alex como "grandes leitores": "Eles conseguem ler até a letra cursiva [...]E, ainda mais, eles só têm 6 anos". Ela se biografa comparando-se a eles: "Eu ainda tô aprendendo"; "Eu tenho 6 anos", ou seja, eu ainda não sou uma criança leitora, "apesar" dos meus seis anos. Os critérios para construir-se como sujeito leitor, desde cedo, são dados (por injunção) pelo discurso escolar: “...ler até a letra cursiva". Contrariamente às demais crianças, Liliana (6,0 anos) não se limita a contar o que ela faz na escola, mas adianta-se aos demais ao falar do "futuro", de seu "projeto" de vida: "Agora eu já sei... [a escola serve] também, quando crescer, estudar muito". Seu horizonte de expectativas se desenha como um percurso a ser feito com cada vez mais afinco nos estudos, em que ela se projeta como agente do seu fazer: [quero/devo/ vou] "estudar muito".

As crianças começam a sobrepor à cultura do estudar, a cultura do brincar. $\mathrm{E}$ à medida que a infância vai se distanciando, cada vez mais, elas vão organizando o enredo da história em que aprender e brincar são atividades diferentes, que acontecem em lugares e tempos diferentes, na escola... e, portanto, na vida.

\section{Final do percurso. Grupo 4: a escola é para aprender, se não...}

As crianças na faixa etária entre 9 e 10 anos tecem comentários sobre os aportes da escola para suas vidas futuras. As palavras"aprender", "estudar" e"ensinar" são de longe as mais frequentes em suas narrativas. Em ambas as escolas, elas consideram que "A escola é legal, porque a gente aprende, a gente estuda, aprende coisas novas"; "Pra mim, a escola é muito legal". A escola vem assim preencher uma nova necessidade: a necessidade de aprendizagem dos conteúdos escolares. Nessas narrativas, as professoras ocupam um lugar central: "A escola é muito legal porque as professoras ensinam outras coisas que a gente não sabe"; "A gente não sabe o significado da palavra, aí, aqui na escola, a professora vai lá e ensina pra gente o que é”. Consideram a diferença entre dois espaços de aprendizagem: as aprendizagens que realizam na escola e as que fazem em casa: "É legal, porque, aqui, a gente pode aprender coisas que em casa a gente não aprende"; "Você aprende matemática, que eu não sei, português e inglês, história e geografia"; "Tema de pesquisa"; "Caligrafia, porque a gente tá escrevendo um livro só do $3^{\circ}$ ano". A figura da professora é a de quem os acompanha na tarefa de aprender como partícipe desse processo. 
A ideia de um horizonte de expectativas passa doravante a dar sentido à escola. Para Tobias e Natália,"[a escola] serve para aprender, porque senão existisse escola a gente seria burro"; "Burríssimo!"; "Por exemplo, alguém perguntava, ei fulano, quanto é $2+2$ ?, aí a gente respondia 1 (um)" [risos]; "A pessoa não aprenderia”. Essa pequena narrativa é reveladora da presença em suas vidas de uma espreita eventual de fracasso, que certamente é aprendida no contato com os adultos. O prejuízo ao desenvolvimento intelectual que ameaça, em surdina, suas trajetórias poderia acarretar como consequência a exclusão social e discriminação, colocando-os em situações sociais de vexame diante do outro. A figura do "burro", "burríssimo" tão emblemática das anedotas escolares faz parte do imaginário escolar e guia as ações da criança no processo de enculturação e de constituição de sua identidade escolar. Para participar dos rituais escolares de "consagração" e evitar aqueles de "exclusão" é preciso se demarcar dessa figura: eu não posso "ser burro", eu "preciso" estudar para ser inteligente, se não...

\section{E portanto ainda brincamos}

Embora reconheçam que faz parte dos seus deveres de bom aluno acatar o que aescola impõe como necessidade de dedicar-se aos estudos para construírem percursos de êxito, as crianças, nessa faixa etária, desenvolvem táticas, no sentido concebido por Certeau (1994, p. 81- 106), para contar com cuidado que não gostam das atividades escolares. Para Tobias, um planeta sem escolas "é trágico"! Ao que Lia contesta: "Você disse que não gostava [da escola]". Na conversa, contornam a situação de negar a palavra do outro, num clima de cumplicidade entre eles.

Quando pedimos que dissessem ao alienígena de que elas mais gostavam na escola, nenhuma criança fez referência à aprendizagem, nem à sala de aula como lugar preferido na escola. Seus lugares prediletos são aqueles em que ainda podem brincar: "Para mim, seria a quadra da Nike"; "É uma quadra que fica aqui embaixo"; "Eu prefiro o solário"; "Lá, a gente fica brincando e não fica preso". E se fossem professores o que fariam para ter uma escola legal?: "Parque, educação física e aulas de artes"; "Filmes todo dia"; "Eu amo assistir filmes"; "Uma atividade por dia e bem facinha..." [risos]. Em suas narrativas, as crianças vão se biografando nessa tensão entre um modo de ser criança e um modo de se constituir aluno pela injunção da necessidade de estudar, de aprender em função de seus projetos futuros. Essa representação de si opõe a liberdade de ser e de fazer o que gosta "eu amo assistir filmes" há a sensação de se sentirem enclausurados: "Lá [longe daqui] a gente [...] não fica preso".

Entre o parque, onde brincam, e a sala de aula, onde estudam, elas vivenciam na sala de informática um outro tipo de relação entre o brincar e o estudar. Trata-se de um outro lugar preferido, porque a "Informática", para elas, permite associar o "brincar" e o "pesquisar", em suma o prazer de descobrir por si mesmas e entre elas: "Lá [na sala de informática] a gente brinca, pesquisa e... essas coisas". Se fosse possível: "Eu faria só UCA"; [O que é UCA?]; "É um computador para cada aluno". Para as crianças que nasceram sob a égide da imagem - são nativos digitais - a sala de informática parece preencher, na escola, ao mesmo tempo, suas necessidades de brincar e de estudar, talvez porque "pesquisar" aparece dissociado do estudar, das atividades e das "tarefinhas".

Podemos afirmar, então, que a necessidade de brincar não desaparece sob a imposição da necessidade de aprender, e estudar para ser melhor no futuro. Tal 
necessidade, nessa etapa, ao contrário, é guardada e preservada pelas crianças, que vãoelaborando, ao lado da autobiografia escolar, uma outra autobiografia: a da liberdade e a da imaginação, em que dão sentido às suas táticas para se manterem crianças. Para Michel de Certeau (2001, p. 104), as táticas são os "gestos hábeis do 'fraco' na ordem estabelecida pelo 'forte', arte de dar golpes no campo do outro, astúcia de caçadores, mobilidades nas manobras, operações polimórficas, achados alegres, poéticos e bélicos". E é essa narrativa biografada no avesso da narrativa escolar que elas contarão, mais tarde, quando os anos tiverem apagado o que lhes foi imposto na constituição de um ethos escolar, que elas dirão como se tornaram sujeitos.

\section{No futuro, vou ser um adolescente. E aí? Ainda vou brincar?}

O horizonte de expectativas das crianças entre 08 e 10 anos é aquele dos irmãos, primos e amigos mais velhos: o mundo dos adolescentes. Ao explicarem para o ET a vida na escola, Tobias, Natália e Lia vão encadeando a seguinte descrição: “É legal [aqui]"; "Ei, ET... Escola, ah... nela, a gente aprende... Tem recreio, alguns são adolescentes, não têm parque. Mas, quando a gente é criança, felizmente, tem parque"; "Porque os adolescentes, eles não brincam"; "Eles ficam só fazendo aquelas coisas que a gente acha chato para as crianças, mas, adolescente acha legal"; [Por exemplo?];"Ficar sentado numa cama, de frente ao computador, ouvindo música... conversando... também fofocando... [Risos]". As crianças, em suas narrativas, biografam o mundo do adolescente, que em breve vão habitar, como um mundo oposto ao de sua infância pela ausência de espaços para brincar: em suas escolas, "não tem parque" [pois] "eles não brincam".

$\mathrm{Na}$ adolescência, completa-se o círculo dessa trajetória dos primeiros anos de escolaridade, que se fecha pelo rompimento (aparente) dos laços com o brincar. A escolarização vai aos pouco esgarçando esses laços, e as crianças de 04 a 10 anos, no seu processo de enculturação, vão incorporando os rituais e os discursos da escola e sendo levadas a soltar as amarras que as enlaçam a sua infância. Em suas narrativas, elas vão autobiografando como aprendem, sem jamais dizer que aprendem, o que lhes ensinam suas silenciosas táticas na arte de se manter crianças; tecer amizades; conviver com o outro; por em uso sua reflexão nos jogos entre eles e nos jogos de poder que experienciam nas brincadeiras, na reinvenção dos espaços escolares, movimentos nos quais se reinventam ao reinventar o tempo que passam na escola. Mas, a reflexão sobre as narrativas das crianças da pesquisa sobre suas brincadeiras, deixamos para o próximo capítulo dessa história a ser escrito com elas.

\section{Considerações em aberto: "Para ficar na escola, ele vai precisar cortar as asas"}

Para ficar na escola ele [o ET] vai precisar cortar as asas, porque na escola não é para voar [...] na escola, é preciso ficar quietinho e estudar para não atrapalhar as crianças, o que as crianças estão pensando... (Giovana e Otávio, 6 e 7 anos).

Apresentamos aqui o que as crianças nos ensinaram até agora sobre seu percurso nos primeiros anos da escola. Nesse início de conversa, procuramos analisar como elas autobiografam essas experiências da infância. O que nos dizem, nessas narrativas, é que se desejarmos promover um acolhimento condizente com seus desejos 
de autonomia, de agência e de protagonismo, é importante que se leve a sério as possibilidades de escutá-las e de legitimar sua reflexão sobre o pensam que fazem, como fazem, e como aprendem a ser, e a conhecer nas escolas que as acolhem na infância.

A epígrafe, com a qual abrimos o desfecho dessas análises iniciais, são excertos da narrativa elaborada coletivamente por Giovana e Otávio que, entre 6 e 7 anos idade, sintetizam parte do que conseguimos depreender em nossas análise sobre a travessia da pré-escola ao ensino fundamental, e, sinalizam inúmeras pistas de investigação. Essas crianças constroem juntas sua visão da escola como um espaço em que devem conter os movimentos do corpo: "ficar quietinho", não voar, exercitar seu autocontrole e respeitar as regras da escola. Vygotski (1998) lembra que uma das funções da brincadeira, na infância, é mediar a autorregulação e o autocontrole dos movimentos e desejos da criança. E, se isso se faz porque elas vão narrando na brincadeira uma história em que assumem um papel imaginário. Nesse "faz de conta", elas interpretam as situações e decidem não agir impulsivamente, mas de acordo com as regras sociais estabelecidas no jogo que elas próprias criaram por necessidade de agir. É por isso que podemos estudar com Bakhtin (1992) o impacto da reversibilidade da palavra sobre o pensamento e afirmar que ela afeta a atitude de quem narra face à dimensão empírica da realidade histórica.

A reflexividade autobiográfica, que a criança realiza no ato de narrar, seja na brincadeira, seja no cotidiano escolar, vai ampliando seu repertório de visões de mundo, as vezes conflitantes, e por essa mesma razão vão se situando na coletividade e vão dando sentido ao que começam a entender por cooperação entre elas como forma de "viver juntos". Não voar, na escola, tem um sentido: "não atrapalhar", nem as crianças, que estão "quietinhas" estudando, sentadas em suas mesinhas, na sala da escola; nem "o que as crianças estão pensando". Giovana e Otávio interpretam, em sua narrativa, os dois panoramas dos quais nos fala Bruner: o da ação externa, no qual os personagens que colocam em cena são crianças que estudam, e um panorama interno: "o que estão pensando", o seu mundo interior, o que estão concebendo, criando, refletindo... e isso não pode ser perturbado, "atrapalhado", pois o que pensam é muito importante...

Simbolicamente, "cortar as asas" fará do ET uma criança como elas: ele deve "ficar quietinho e estudar". Furlanetto e Oliveira (2013), ao analisar essa mesma cena, se interrogam sobre a institucionalização do corpo na escola. Como a criança aprende a lidar com seus próprios movimentos? Em que medida os rituais escolares impõem/ dissuadem/encorajam a conjugar o movimento do corpo com aqueles da emoção, da liberdade, do respeito ao outro...? Essas são pistas apontadas pelas crianças e que nos mostram o quanto estamos longe, em nossas pesquisas, de aprofundarmos o que está latente em suas falas, em seus gestos.

Se é verdade que o humano, desde tenra infância é um ser contador de histórias, capaz de refletir sobre suas experiências, a investigação que faz uso das narrativas de si, como objeto de estudo e método pesquisa tem um duplo mérito: levar a criança a refletir sobre ela mesma na atividade de biografização e o pesquisador a refletir sobre si mesmo ao escutar, ler, analisar, publicar as narrativas que lhe são contadas. De modo que a atividade de biografar-se não traduz apenas o conhecimento que adquirimos sobre o objeto de estudo, mas nos ajuda a reelaborar o conhecimento de nós mesmos enquanto pesquisadores e a rever nossas responsabilidades inter(intra) geracionais. Ao se convidar as crianças de 04 a 10 anos de idade arefletir sobre suas 
Maria da Conceição Passeggi - Ecleide Cunico Furlanetto - Luciane De Conti

Iduina Edite Mont'Alverne Braun Chaves - Marineide de Oliveira Gomes

Gilvete Lima Gabriel - Simone Maria da Roch

experiências nas escolas da infância, multiplicam-se, a um só tempo, novos espaços de produção de conhecimento e de formação humana. Por se tratar de aspectos profundamente imbricados na pesquisa, é que podemos falar de pesquisa-formação ou de pesquisa-ação-formação como sugere Gaston Pineau (2004), um dos pioneiros do movimento das histórias de vida em formação.

Os aportes de pesquisas dessa natureza confirmam que o diálogo com as novas gerações é prejudicado por uma percepção da infância construída em torno do que a criança "ainda" não possui. E, essa visão está de tal forma arraigada em nossa cultura de adulto que é difícil começar o diálogo pelo que a criança "já" possui. Apesar de se observar cada vez mais as habilidades da criança desde o seu segundo ano de vida com o mundo digital, custa admitir, por exemplo, que desde tenra infância ela é capaz de refletir sobre sua experiência. Ou ainda melhor, reconhecer que a criança pequena tem experiências e que é capaz de refletir sobre elas. Esta é uma de nossas principais conclusões, que embora permeada por toda sua complexidade, nos encoraja a continuar a fazer da narrativa nosso objeto de estudo e instrumento potencialmente rico para os estudos da criança e das escolas da infância. Esses achados, em andamento, sinalizam a riqueza de suas pequenas narrativas e de seus modos de se biografarem nas escolas da infância. Pudemos observar como elas vão construindo, narrativamente, figuras de si, na composição do enredo, em suma, a sua identidade narrativa, como teorizou Paul Ricoeur (1994). Estamos longe de explorar o que nos disseram e o que têm ainda anos dizer. A sua mais sábia lição nos leva a concordar com Hannah Arendt (2008) que para compreender é preciso narrar. Mas, esperamos que essa atividade imemorial do humano não seja enquadrada como um rito de iniciação nas escolas da infância.

\section{Referências}

ARENDT, H. Compreender. Formação, exílio, totalitarismo. São Paulo: Companhia das Letras, 2008.

BAKHTIN, M. Estética da criação verbal. Tradução Ermantine Galvão. São Paulo: Martins Fontes, 1992.

BERTAUX, D. Narrativas de vida. A pesquisa e seus métodos. Trad. Zuleide Cavalcante e Denise Lavallée e Natal, RN: EDUFRN; São Paulo: PAULUS, 2010.

BOURDIEU, P. (Coord.). A Miséria do mundo. Tradução Mateus S. Soares Azevedo et al. 5a ed. Petrópolis: Vozes, 2003.

BRASIL. Lei Federal n. 9.394/96 - Lei de Diretrizes e Bases da Educação Nacional. Acessível em: <http://www.planalto.gov.br/ccivil_03/leis/19394.htm>. Acesso em: 03 nov. 2013.

BRASIL. Constituição da República Federativa do Brasil, 1988. Acessível em: <http://www. planalto.gov.br/ccivil_03/constituicao/constituicao.htm>. Acesso em: 02 nov. 2013.

BROCKMEIER, J.; HARRÉ, R. Narrativa: problemas e promessas de um paradigma alternativo. Psicologia: Reflexão e Crítica, Porto Alegre, v. 18, n. 3, p. 525-535, 2003.

BRUNER, J. Atos de significação. Porto Alegre: Artes Médicas, 1997.

BRUNER, J.; WEISSER, S. A invenção do ser: A autobiografia e suas formas. In: OLSON, D.R.; TORRANCE, N. Cultura escrita e oralidade. São Paulo: Ática, 1995, p. 141-161.

CERTEAU, M. de. A invenção do cotidiano. 1. Artes de fazer. Petrópolis, Rio de Janeiro: Vozes, 1994. 
CORREIA, M. F. B. A constituição social da mente: (re)descobrindo Jerome Bruner e construção de significados. Estudos de Psicologia. 8(3) 505-513, 2003.

CORSARO, W. A. Métodos etnográficos no estudo da cultura de pares e das transições iniciais na vida das crianças. In: MÜLLER, F. (Org.). Teoria e prática na pesquisa com crianças: diálogos com W. Corsaro. São Paulo: Cortez, 2009, p. 83-103.

CRUZ, S. H. V. (Org.). A criança fala: a escuta de crianças em pesquisas. São Paulo: Cortez, 2008.

DELALANDE, J.; DANIC; I.; RAYOU, P. Enquête auprès d'enfants et de jeunes. Objets, méthodes et terrains de recherche. Rennes: PressesUniversitaires de Rennes, 2006.

DELORY-MOMBGERGER, C. Abordagens metodológicas na a pesquisa biográfica. Revista Brasileira de Educação. v. 17, n. 51, p. 523-536, set./dez. 2012

FERRAROTTI, F. Sobre a autonomia do método biográfico. In: NÓVOA, A.; FINGER, M. (Orgs.). O método (auto)biográfico e a formação. Natal, RN: EDUFRN; São Paulo: PAULUS, 2010, p. 31-57.

FERREIRA, M. M. Martinho. "Branco demasiado" ou... Reflexões epistemológicas, metodológicas e éticas acerca da pesquisa com crianças. In: SARMENTO, M.; GOUVÊA, M. C. S. de (Orgs.). Estudos da infância: educação e práticas sociais. Petrópolis: Vozes, 2008, p. 143-162.

FORTUNA, T. Sala de Aula é lugar de brincar? Disponível em: < http://brincarbrincando. pbworks.com/f/texto_sala_de_aula.pdf>, Acesso em: 12 maio 2013.

FURLANETTO, E.; OLIVEIRA, M. G. de. Para estar na escola é necessário cortar as asas: as narrativas acerca da institucionalização da infância e do corpo nas escolas. (No prelo)

GOUVEA, M. C. S. (Orgs.). Estudos da Infância: Educação e práticas sociais. Rio de Janeiro: Vozes, 2008, p. 17-39.

LANI-BAYLE, M. (Dir.). Raconter l'éco le encours du siècle, Paris: L'Harmattan, 2000.

LARROSA, J. Pedagogia profana: danças, piruetas e mascaradas. Belo Horizonte: Autêntica, 2010.

LEE, N. Vozes da criança, tomada de decisão e mudança. In: MÜLLER, F. (Org.). Infância em perspectiva. Políticas, Pesquisa e Instituições, São Paulo: Cortez, 2010.

MILLS, C. W. A imaginação sociológica. Tradução se Waltersir Dutra. 6a ed. Rio de Janeiro : Zahar Editores, 1982.

MOUTINHO, K; DE CONTI, L. Considerações sobre a Psicologia da Arte e a Perspectiva Narrativista. Psicologia em Estudo. v. 15, p. 685-694, 2010.

MÜLLER, F. (Org.). Infância em perspectiva. Políticas, Pesquisa e Instituições, São Paulo: Cortez, 2010.

MÜLLER, F.; CARVALHO, A. M. A. (Orgs.). Teoria e prática na pesquisa com crianças: diálogos com William Corsaro. São Paulo: Cortez, 2009.

PASSEGGI, M. da C. A experiência em formação. Revista Educação, Porto Alegre, v. 34, n. 2, p. 147-156, maio/ago. 2011a.

PASSEGGI, M. da C. A pesquisa (auto)biográfica em educação: princípios epistemológicos, eixos e direcionamentos da investigação científica In: VASCONCELOS, F.; ATEM, É. Alteridade: o outro como problema. Fortaleza: Expressão Gráfica, 2011 b.

PASSEGGI, M. da C.; BARBOSA, T.M. (Org.). Memórias, memoriais: pesquisa e formação. Natal, RN: EDUFRN; São Paulo: PAULUS, 2008. 
Maria da Conceição Passeggi - Ecleide Cunico Furlanetto - Luciane De Conti

Iduina Edite Mont'Alverne Braun Chaves - Marineide de Oliveira Gomes

Gilvete Lima Gabriel - Simone Maria da Roch

PINO, A. As marcas do humano: as origens da constituição cultural da criança na perspectiva de Lev S. Vigotski. São Paulo: Cortez, 2005.

PROUT, A. Participação, políticas e as condições da infância em mudança. In: MÜLLER, F. (Org.). Infância em perspectiva. Políticas, Pesquisa e Instituições, São Paulo: Cortez, 2010, p. 21-41.

RICOEUR, P. Tempo e Narrativa. Tomo I Campinas: Papirus, 1994.

RIVIERE, C. Enculturation. In: AKOUN, A. ; ANSART, P. (Dir). Dictionnaire de sociologie. Paris: Le Robert, 1999, p.183.

SACRISTÁN, J. G. O aluno como invenção. Porto Alegre: Artmed, 2005.

SARMENTO, M. J. As crianças e a infância: definindo conceitos, delimitando o campo. In: SARMENTO, M. J. ; PINTO, M. (Orgs.). As crianças: contextos e identidades. Braga: Universidade do Minho, 1997, p. 7-30.

SARMENTO, M. J.; VASCONCELOS, V. M. (Orgs.). Infância (in)visível. Araraquara: Junqueira \& Marin, 2007.

SARMENTO, M. J ; PINTO, M. (Orgs.). As crianças: contextos e identidades. Braga: Universidade do Minho, 1997.

SMITH, V. A construção do sujeito narrador: linguagem, organização do pensamento discursivo e a imaginação. Tese de Doutorado. Porto Alegre: Universidade Federal do Rio Grande do Sul, 2006. SMITH, V.; BORDINI, G. S.; SPERB, T. M. Contextos e parceiros do narrar de crianças na escola infantil. Psicologia: Reflexão e Crítica, 22 (2), 181-190, 2009.

SMITH, V.; SPERB, T. M. A construção do sujeito narrador: Pensamento discursivo na etapa personalista. Psicologia em Estudo, 12(3), 553-562, 2007.

VYGOTSKI, L. S. Conscience, inconscient, émotions. Paris: La Dispute, 2003.

VYGOTSKY, L. S. A formação social da mente. São Paulo: Martins Fontes, 1989.

\section{Notas}

${ }^{1} \mathrm{O}$ Projeto "Narrativas infantis. O que contam as crianças sobre as escolas da infância?", em andamento, é financiado pelo Edital de Ciências Humanas [CNPq/CAPES 07/2011-2, Processo no 401519/20112],e desenvolvido por pesquisadores de seis universidades: UFRN, UFPE, UNICID, UNIFESP, UFF e UFRR. Aprovado pelo Comitê de Ética [Parecer no 168.818]. A pesquisa integra um projeto internacional "Raconterl'écoleencours de scolarisation", coordenado por Martine Lani-Bayle (Universitéde Nantes), desenvolvido, em rede,por pesquisadores da França, Polônia, Bélgica, Suíça, Brasil.

${ }^{2}$ Alterações instituídas na LDBEN no 9394/96, pela Lei no 12.796 de 2013 e pela Lei no 11.274/2006.

${ }^{3}$ De acordo com o que ficou estabelecido no TCLE, aprovado pelo Comitê de ética, os nomes das crianças são fictícios para preservar o anonimato.

${ }^{4}$ Uma ampla bibliografia a esse respeito pode se encontrada nas coleções que resultam das diferentes edições dos Congressos Internacionais de Pesquisa (Auto)Biográfica e no banco de teses da CAPES. Cf. Passeggi; Barbosa, 2008; Passeggi, 2011. 
* Professora Doutora da Universidade Federal do Rio Grande do Norte, Natal, Rio Grande do Norte Brasil.

** Professora Doutora da Universidade Cidade de São Paulo, São Paulo, São Paulo - Brasil.

*** Professora Doutora da Universidade Federal de Pernambuco, Recife, Pernambuco - Brasil.

***** Professora Doutora da Universidade Federal Fluminense, Rio de Janeiro, Rio de Janeiro - Brasil.

***** Professora Doutora da Universidade Federal de São Paulo, São Paulo, São Paulo - Brasil.

****** Professora Doutora da Universidade Federal de Roraima, Boa Vista, Roraima - Brasil.

******** Professora Doutoranda da Universidade Federal do Rio Grande do Norte, Natal, Rio Grande do Norte - Brasil.

\section{Correspondência}

Maria da Conceição Passeggi - Rua Alameda das Margaridas 1275, ap. 201, Ed. Victor Hugo - Tirol, CEP: 59. 020-580, Natal, Rio Grande do Nortre - Brasil.

E-mail: mariapasseggi@gmail.com - ecleide@terra.com.br - ludeconti@gmail.com - iduina@globo.com

- neide.ogomes@gmail.com - gilvetelima@yahoo.com.br - siufrn@yahoo.com.br

Recebido em 13 de outubro de 2013

Aprovado 27 de novembro de 2013 
